\title{
CONTROLLING DEFECTIVE ITEMS IN A COMPLEX MULTI-PHASE MANUFACTURING SYSTEM
}

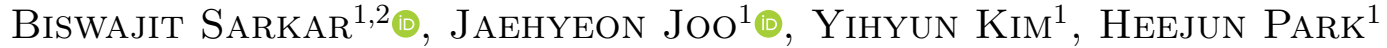 \\ AND MitALI SARKAR ${ }^{3, *}$ (10
}

\begin{abstract}
In manufacturing systems, defective items are produced for machine drift and error. Usually, an imperfect production rate is random, and if the items are not reworked, these are considered trash and harm the environment. The proposed model aims to reduce waste by reworking defective products and maximizing profit. For profit maximization or overall cost minimization of the manufacturing system, setup cost has significant. A discrete investment for each phase is introduced with an inequality investment constraint for reducing the setup cost. Selling price-dependent demand is trained for more generalized applications for various industries. The proposed model is a multi-phase manufacturing system with optimum batch size, selling price, and investment with an irregular, imperfect production rate. Defects are detected at the first inspection, and the reworked items are checked if the reworked items are all non-defective in the second inspection. The model conducts a two-stage inspection. One is for detecting defective items, and another is for checking if all items are not defective after reworking. The model is solved with the Karush-Kuhn-Tucker (KKT) method, and the global maximum profit is obtained. The model shows that all investments should be assigned to maximize the profit and the optimal solution. Reducing setup cost with the investment is better than a constant setup cost.
\end{abstract}

Mathematics Subject Classification. 90B05, 90B06.

Received July 27, 2021. Accepted February 5, 2022.

\section{INTRODUCTION}

Awareness about environmental protection has spread among industries, and manufacturers reduce pollution in manufacturing systems. The research aims to diminish waste, which can be achieved by lowering defective manufacturing processes. The proposed study explains a multi-phase manufacturing system (MPMS), a significant research gap compared to other research about cost optimization models in a single-phase production. An out-of-control state influences the entire process in an MPMS and ends up in many defective items. Since these defective products directly generate waste, coming up with methods to rework these defective items is

Keywords. Manufacturing systems, remanufacturing, makespan, investment appraisal, inspection.

1 Department of Industrial Engineering, Yonsei University, 50 Yonsei-ro, Sinchon-dong, Seadaemun-gu, Seoul 03722, South Korea.

2 Center for Transdisciplinary Research (CFTR), Saveetha Dental College, Saveetha Institute of Medical and Technical Sciences, Saveetha University, 162, Poonamallee High Road, Velappanchavadi, Chennai 600077, Tamil Nadu, India.

3 Information Technology Research Center, Chung-Ang University, Seoul 06974, South Korea.

* Corresponding author: mitalisarkar.ms@gmail.com 
desirable. The proposed model assumes no shortage in the manufacturing system due to difficulty interpreting the randomness of defects and claims defective items to be reworked within the same cycle.

Another critical implication this model suggests is the role of the discrete investment function in reducing setup. Considering the reduction in setup cost through investment is inevitable when decreasing defective items because an MPMS has an expensive setup cost. The proposed model assumes discrete investment in reducing setup costs in an MPMS. It considers the compensation between setup and investment cost. Therefore, an inequality constraint for the investment budget is considered. Besides, the model uses selling price-dependent demand instead of constant demand. High selling price negatively affects customers' consumption of a product or service; thus, it is more practical to assume demand to be selling price dependent.

The following questions arise from the research study:

- For each production system, it is found that there is a huge amount of waste, which makes it difficult for the industry to manage them [26]. For this reason, the proposed study is considered for an MPMS. Any production system stage may move to an uncontrollable state at any time. Owing to that situation, the system starts to produce defective products randomly. Those defective products are treated as waste because those products cannot be sold at that state. How does the randomly generated waste be reduced from the MPMS?

- The setup cost is necessary for any multi-stage production system at each stage. If defective products are produced at each stage, the system either needs to produce more products or rework the defective products. The process requires an immense setup cost, which restricts gaining more profit. The manufacturer wants to gain more profit by reducing excess setup costs. What is the process that the manufacturer can reduce the setup cost?

- The demand of a manufacturing system may be constant or variable. It is more realistic that the demand is variable. Generally, if the selling price of products becomes high, most customers do not want to buy more products and vice versa. Why is the selling price dependent demand preferable to a constant demand for this study?

- The proposed model is a non-linear optimization problem. An analytical solution is needed to find the optimum decision variables and profit. Which methodology should be adopted to optimize the profit and why?

The answers to the above research questions are explained below, which is the research gap of this study.

- The proposed research reduces waste by reworking defective products in the cycle in an MPMS without shortages. The investment budget is used to reduce the setup cost, which can significantly impact the total profit because setup cost accounts for a significant expense of the multi-phase manufacturing system. The setup cost can be reduced by discrete investment as an inequality constraint and price-dependent demand. Since this model uses a discrete investment function and an inequality constraint on budget usage, total profit can increase, considering that all investment budgets might not be allocated due to a trade-off between costs.

- The total profit can vary as the demand changes along with the change in selling price. The parameters related to selling price and demand can be tuned to calculate the sensitivity of the change in total profit.

- A non-linear cost function is optimized by calculating the optimal batch size, investment per phase, and selling price. The KKT method is adopted to solve the model to analyze the research problems. KKT method is a first-order necessary test for solving a non-linear programming model with regularity conditions. It is useful when obtaining global optimum when there are inequality constraints in a closed and bounded form of the continuous objective function.

This paper's framework is as follows: Section 2 contains the literature review; the problem definition, notation, and assumptions are in Section 3. The mathematical model and solutions are introduced in Section 4. The numerical experiments, sensitivity analysis of critical parameters, and managerial insights are provided in Section 5. Section 6 provides the conclusions, the limitations, and future works of the proposed research. 


\section{Literature REVIEW}

\subsection{Waste reduction through remanufacturing}

Defective items are produced due to machines' breakage or human error directly produce waste. Therefore, studies about accurate inspection and reworking schedules are necessary. Methods to reduce defective items in a manufacturing process by minimizing cost were discussed in many research pieces. Saxena et al. [31] developed a mathematical model to analyze replenishment cycles with respect to waste management and explained how adopting the right waste-reducing policy reduces total cost. Garai and Sarkar [16] reduced waste by remanufacturing of new products from waste. Sarkar and Sarkar [28] proposed a model that produces pure biofuel consuming minimum energy through a classical optimization technique. Optimal retailer investment was used to attempt defective accessible environments invented by Saha et al. [24] in a single-phase manufacturing system.

Gayon et al. [11] studied the reusable products' random return through two methods. Different types of disposing options and product reworking procedures were used, not in the view of a multi-phase manufacturing system. The proposed model has a significant research gap compared to other articles considering a waste reduction in the manufacturing system because it assumes a multi-phase manufacturing system. Furthermore, research studies modelling various probability distributions of defectiveness, but according to Sarkar [26], it is still tricky to handle defective goods' uncertain production. Effects of learning and forgetting in manufacturing systems and reworking procedures are considered in Glock and Jaber [12], and Tayyab and Sarkar [36] calculated optimum batch size if random, imperfect rate follows beta distribution density function. The proposed model does not explain the type of distribution but only considers the defective rate's random distribution, assuming no shortage in the manufacturing system.

Yadav et al. [42] utilized several sustainability policies and preservation technology to maintain the number of products and reduce waste. Mahapatra et al. [19] planned to reduce wastes coming from deteriorated products in the same direction. They proved that the circular economy concept could be formed by lowering total cost minimization waste. Sepheri et al. [32] reduced waste from the deteriorated products under an inventory system through the idea of preservation policy. They proved that waste and the total cost could be minimized through an effective preservation strategy. Ahmed et al. [1] demonstrated that the retail industry could profit using trade credit policy. Still, they did not bother about the multi-stage production process, investment, or waste reduction.

\subsection{Discrete investment}

There are many kinds of research about setup cost reduction by investment. In Kim and Sarkar's [17] model, a multi-layered trade-credit strategy for a short-term investment was introduced. Golari et al. [13] introduced a generation capacity variable to reflect its investment in different renewable generation types. However, all the results focused on a single-phase production model. Other articles consider investment in a multi-phase production model. Continuous investment in an MPMS was studied by Glock and Jaber [12]. The research assumed that the products could not constantly be reworked in the same phase. Tayyab and Sarkar [36] studied an MPMS with continuous investment. Work in process inventory was not considered, and the policies of cost reduction. They made an unrealistic assumption and assumed a backorder rate for the shortage of most products. Due to this, a more generalized model was required for research gaps.

Golari et al. [13] conducted an MPMS study and constant setup cost without considering an investment. They did not account for the defective items created in various phases. This research focuses on a continuous investment function, which is unnecessary if discrete investment entirely decreases setup cost. The proposed model has a research gap in introducing discrete investment to reduce setup costs in an MPMS to cut waste. Whenever an industry runs a multi-stage, complex, or smart production system, the major issue is obtained from the setup cost of that production system, whatever it may be, a complex, multi-stage, smart production system. Thus, any investment can be applied to reduce the setup cost, which may be continuous or discrete, based on the industry's situation. 
Bhuniya et al. [4] proved that the investment could reduce the setup cost. Based on the situation of the manufacturing system, the investment can be modified from continuous to discrete or discrete to continuous. Without the specification of continuous, discrete investment, Vandana et al. [34] considered a cost for energy for each cost in their model. They proved that renewable energy could be utilized as a specification of the investment for the long term, and they established the global minimum profit through it.

\subsection{Multi-phase manufacturing system}

The proposed model explains a multi-phase manufacturing system. It is a significant research gap compared to other research about cost optimization models in a single-phase production. Optimal retailer investment was used to attempt defective free environments invented by Saha et al. [24]. They missed out on a significant factor: the manufacturing system was a multi-phase operation. To obtain the best optimal production batch quantity, Tayyab and Sarkar [36] attempted to invent a surpassing way of the production process. Work in process inventory was not calculated when making the multi-phase lean production as they only considered finished product inventory. They also left out one of the most critical factors being total system cost reduction when setting up the multi-phase production.

An MPMS best reflects reality, but at the same time, it is supposed to be very difficult to handle. When defective products are reworked after the end cycle, unusable imperfect items appear in each phase, resulting in shortages. Since the proposed model assumes no shortage in the manufacturing system due to difficulty interpreting defects' randomness, the model claims defective items to be reworked within the same cycle. Whether defective items should be reworked in the same phase or after the end cycle is discussed in Sarkar [26]. Ullah and Sarkar [39] proved the benefit of remanufacturing with the help of return products. However, they did not mention about the stage of production, and they only considered the concept of technological growth and logistics growth.

Ullah et al. [40] extended Ullah and Sarkar's [39] model with the major effects of remanufacturing under a logistics chain. They proved that remanufacturing could reduce the production cost provided that no defective product would be produced during remanufacturing. Though dear considered several logistic benefits, day relax the adoption of a multi-stage production system, where the major research gap exists. If lead time exists, how to deal with random lead time demand, provided by Dey et al. [6]. Even though they did not bother about multi-phase production to control the random demand. Gupta et al. [14] proved the benefit of multi-product production under a supply chain management, where uncertainty is a major issue. Due to the uncertainty issue, Gupta et al. [14] solved the model with fuzzy methodology but still considered only the single-stage production system without having any concept of waste reduction during the production of products.

Hashan et al. [21] developed a preservation policy to maintain the quality of products for the retail industry without having any concept of the manufacturing industry. They only concentrated on the profit of the retailing industry if products were already reached from manufacturer to retailer. Therefore, they did not have any concept of the manufacturing industry.

\subsection{Selling price dependent demand}

This research is about multi-phase manufacturing systems with fixed demand. Most of the multi-phase production models assume demand to be constant. Effects of learning and forgetting were considered in a serial MPMS given a constant demand over a planning horizon in Biel and Glock [3]. A multi-period, manufacturingstock scheduling model of a multi-plant production system assuming a fixed demand per product in a certain period is introduced in Golari et al. [13]. There is research about demand rate being variable depending on time, selling price, inventory in simple inventory models. In Alfares and Ghaithan [2], the flexibility of the demand rate was considered selling price dependent on the inventory model. Forghani et al. [9] introduced the model that the demands depend on the selling price with a price adjustment, and a combined stock model with selling price dependent demand is introduced in Dey et al. [5]. 
TABLE 1. Author contribution table.

\begin{tabular}{|c|c|c|c|c|}
\hline Author(s) & $\begin{array}{l}\text { Waste } \\
\text { reduction }\end{array}$ & Investment & $\begin{array}{l}\text { Production } \\
\text { phase }\end{array}$ & Demand pattern \\
\hline Sarkar $[26]$ & Considered & Discrete & Multi & Constant \\
\hline Glock and Jaber [12] & $\mathrm{N} / \mathrm{A}$ & Continuous & Multi & $\mathrm{N} / \mathrm{A}$ \\
\hline Tayyab and Sarkar [36] & $\mathrm{N} / \mathrm{A}$ & Continuous & Multi & $\mathrm{N} / \mathrm{A}$ \\
\hline Kim and Sarkar [17] & Considered & Discrete & Multi & Normal distribution \\
\hline Golari et al. [13] & $\mathrm{N} / \mathrm{A}$ & N/A & Multi & Random \\
\hline Biel and Glock [3] & $\mathrm{N} / \mathrm{A}$ & $\mathrm{N} / \mathrm{A}$ & Multi & Constant \\
\hline Sarkar et al. [27] & Considered & $\mathrm{N} / \mathrm{A}$ & Single & Random \\
\hline Proposed model & Considered & Discrete & Multi & Selling price dependent \\
\hline
\end{tabular}

Contrary to research about multi-cycle manufacturing systems with fixed demand, every study with variable demand is a single-phase manufacturing system. Weller et al. [41] proposed the impact of additive manufacturing technology at the firm and industrial field. The paper intended to discuss making the customized products without investing any penalty under this additive manufacturing. Weller et al. [41] explained only a single-stage manufacturing process, but Tayyab and Sarkar [36] developed a multi-stage lean manufacturing process. This paper improved the multi-stage production setup with the random defective rate but no discussion on the waste of defective products. Makarichi et al. [20] developed the simple concept for the waste of energy consumption. With this evolution in the waste-to-energy, an industry can understand problems of practical business strategy better.

Moreover, the purpose of this study of Gardas et al. [10] was to identify the causal factor to count the waste/losses of the fruit and vegetable in the single-stage supply chain system. Dowson et al. [8] incorporated a multi-stage stochastic optimization model for the pastoral dairy farm. The model considered only weather and price-sensitive variables. Further, Soloski et al. [35] developed a single-stage waste management policy with specific products: fermentation of lignocellulose and blood platelet separately. Hammad et al. [15] introduced a multi-stage production system for the single product applied to reduce pill burden and its side effects whereas, Moon et al. [38] examined a reliable production system where the goal programming was used to find the degree of difficulty for reliability.

The study of the paper by Meherishi et al. [22] focused on packaging waste in both traditional systems and e-commerce systems. The model compared both centralized and decentralized systems where it was found that there was less packaging waste in the decentralized than in the centralized system. With random demand of real data from industry, how a machine learning approach can provide more profit, Sardar et al. [25] proved by using a normal distribution and a distribution-free approach. How to get more profit through a perfect supplier selection? Omair et al. [23] and Sarkar and Tayyab [37] introduced two different supplier selection policies. The profit will always be global maximum. Kumar et al. [18] proved that the global maximum profit could be obtained through the uncertain demand of a logistic inventory model. Shaikh et al. [33] introduced strategies to gain more profit under the trade-credit policy.

The proposed model has a significant research gap compared to previous studies because it simultaneously assumes demand to be variable in an MPMS. This paper is more practical in real-world applications since it optimizes the selling price as a decision variable to give more insight into the manufacturing industries. Moreover, since the selling price is a decision variable instead of demand, the objective function changes to maximize profit (Tab. 1). 


\section{Problem definition}

The problem definition section elaborates on the research question, assumptions, and the notation used in the optimization.

\subsection{Research problem}

The suggested model improves a manufacturing system by reducing the number of faulty items. It considers a multi-phase manufacturing system. Reducing defective items, which adversely affect the environment, such as factory waste, can be reduced. For the generalized application for various industries, selling-price-dependent demand is adopted for the model. The proposed research reduces wastes by reworking defective products and maximizing the profit with a setup cost reduction of the manufacturing system. The study aims to obtain the optimum batch size, investments of each phase, and unit selling price for the manufacturing systems. The system produces defective items with random rates, and the mean value of the rates is given. A discrete investment function is suggested to reduce the setup cost of each phase. The maximization of the profit of the entire system will be achieved with investment and inequality constraints. Figure 1 shows a description of the multi-phase manufacturing system.

\subsection{Notation}

The notation is adopted for the proposed model.

\subsubsection{Index}

$i \quad$ Phase $(i=1,2, \ldots, n)$

\subsubsection{Decision variables}

$V \quad$ Selling price (\$/unit)

$I_{i} \quad$ Investment of phase $i$

$Q \quad$ Batch size

\subsubsection{Dependent variable}

$D \quad$ Selling price dependent demand (units/year)

\subsubsection{Parameters}

$\alpha \quad$ Annual fractional cost (\$/investment)

$\beta \quad$ Price elasticity parameter

$P \quad$ Production rate (units/year)

$\lambda_{i} \quad$ Proportion of imperfect items

$F_{i} \quad$ Discrete investment function (\$/stage)

I Total expenditure of the manufacturing system for each planning period

$b \quad$ Factor of ratio between setup time and cost (\$/hour)

$U_{i} \quad$ Maximum setup cost of phase $i$

$L_{i} \quad$ Minimum setup cost of phase $i$ (hour)

a Shape parameter for investment per phase

$C_{i} \quad$ Processing cost in phase $i$ per unit (\$/unit)

$S 1_{i} \quad$ Inspection cost for phase $i$

$S 2_{i} \quad$ Inspection cost for phase $i$ for defective items (\$/item)

$H \quad$ Unit inventory carrying cost (\$/unit/year) 

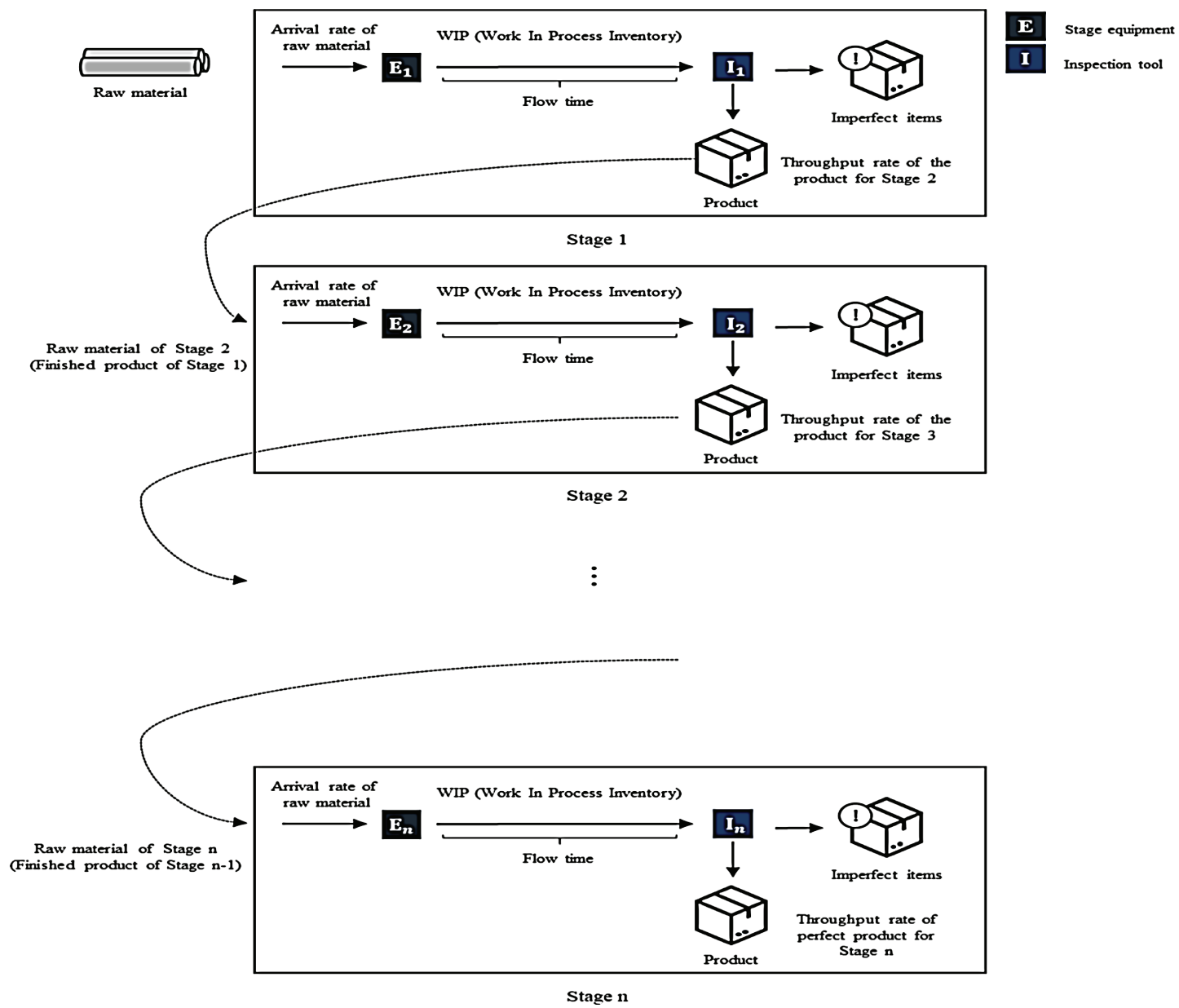

Figure 1. Multi-phase manufacturing system (see for Ref. [26]).

\subsection{Assumptions}

(1) This research's MPMS produces a single type of product with price-dependent demand $D$ and uniform production rate $P$ while planning the products.

(2) The fraction of imperfect items for phase $i(i=1,2, \ldots, n) \lambda_{i}$ is a random variable. Therefore, the perfect production rate $\left(1-\lambda_{i}\right) P$ can be less than the constant demand $D$. This implies that shortage can happen. However, the proposed model considers the case of reworking defective items in the same cycle without shortage.

(3) Defective items are produced when the manufacturing system is unmanageable. The cost of reworking defective items is fixed like Gayon et al. [11]. In each phase, there are two inspection processes. The first inspection process is for all items to detect defective items, and the following inspection process ensures that there are no defects in all reworked items.

(4) In some research papers [17], continuous investments are adopted for setup cost reduction. However, for this research, an MPMS is introduced. Because of introducing an MPMS, a discrete investment function is needed. Thus, discrete investments are used to cut down the setup cost of MPMS. For making the model more accurate, inequality budget constraint is added. The discrete investment function $F_{i}\left(I_{i}\right)$ is a function 
of decision variables $I_{i}$ and its formula is $F_{i}\left(I_{i}\right)=b L_{i}+\left(U_{i}-b L_{i}\right) e^{-a I_{i}}$ where $a$ is the shape constant for the investment of each phase, $b$ is the factor of ratio between setup time and cost. The minimum setup cost of $i$ th phase, which means the reduction level is at maximum is represented as $L_{i}, U_{i}$, the maximum setup cost of phase $i$ when setup cost is not reduced, and $I_{i}$ is the entire expenditure of investment for the system for each production planning horizon.

(5) Selling-price-dependent demand is adopted like Dey et al. [5]. Its formula is $D=\alpha / V^{\beta}$ while $\alpha$ stands for the annual fractional cost, $V$ is the selling price of a unit, and $\beta$ is the price elasticity parameter.

\section{Mathematical model}

This section shows the elaboration of the model and solution methodology of the proposed research.

\subsection{Model development}

The model develops an MPMS that produces a single class of items. The system may move to an uncontrollable state during production, making defective items. A two-stage inspection is conducted to inspect all products. A lot is first inspected to find defective products, and these defects are reworked. After reworking, a second inspection occurs to ensure no defective items. Defective items are continuously produced at a random rate, increasing costs. It is necessary to have an investment to decrease setup costs instead. An inequality budget constraint and a selling-price dependent demand are introduced to make the problem more realistic. The total profit for this MPMS can be calculated as follows:

\subsubsection{Setup cost $(S C)$}

There are $n$ phases in a cycle of the manufacturing system. Therefore, each stage has its own setup cost. In the same cycle, faulty items are reworked over one production horizon period $Q / D$. By multiplying the sum of the discrete investment function $F_{i}\left(I_{i}\right)$ the sum of setup cost (SC) for $n$ phases per cycle can be obtained.

$$
\mathrm{SC}=\frac{1}{Q} \sum_{i=1}^{n} D F_{i}\left(I_{i}\right)
$$

\subsubsection{WIP processing cost $(P C)$}

Processing cost per batch can be calculated by multiplying planned batch size $Q$ unit of each cycle and processing $\operatorname{cost} C_{i}$ in phase $i$ per unit. By multiplying the inverse production horizon period $Q / D$, the processing cost for $n$ phases can be obtained.

$$
\mathrm{PC}=\sum_{i=1}^{n} C_{i} Q \times\left(\frac{D}{Q}\right)=\sum_{i=1}^{n} D C_{i}
$$

\subsubsection{Inspection cost (IC)}

A two-stage inspection is conducted to maintain the quality of the produced goods. The first stage inspects the whole lot to check whether there are faulty items. Therefore, the cost of the first inspection can be calculated by multiplying inspection cost for each stage $S 1_{i}$ and the annual demand $D$. Since the second stage only inspects the reworked imperfect products inspected in the previous stage, the number of goods being examined should be calculated by multiplying the estimated portion of faulty item rproduction rate for phase $i\left(E\left[\lambda_{i}\right]\right)$.

$$
\mathrm{IC}=\sum_{i=1}^{n} S 1_{i} D+\sum_{i=1}^{n} S 2_{i} E\left[\lambda_{i}\right] D .
$$




\subsubsection{Inventory holding cost $\left(I H C_{1}\right)$}

The cost for holding faultless items is calculated by multiplying the average Inventory of perfect worked products for $n$ phases to the unit inventory carrying cost $H$. The initial imperfect rate is $\lambda_{0}=0$.

$$
\begin{aligned}
I_{\text {avergae }} & =\frac{Q}{2 n P}\left[\sum_{i=1}^{n}\left(P\left(1-E\left[\lambda_{i}\right]\right)-D\right) \prod_{j=1}^{i}\left(1-E\left[\lambda_{j-1}\right]\right)\right] \\
\mathrm{IHC}_{1} & =\frac{H Q}{2 n P}\left[\sum_{i=1}^{n}\left(P\left(1-E\left[\lambda_{i}\right]\right)-D\right) \prod_{j=1}^{i}\left(1-E\left[\lambda_{j-1}\right]\right)\right] .
\end{aligned}
$$

\subsubsection{Reworking cost (RC)}

For each phase with planned batch size $Q, E\left[\lambda_{i}\right] Q$ defective items are produced, and the corresponding processing cost is $E\left[\lambda_{i}\right] Q C_{i}$. The reworking cost for $n$ phases can be calculated by summing all phases, and the total reworking cost for the production horizon is obtained by dividing the production horizon period $Q / D$.

$$
\mathrm{RC}=Q \sum_{i=1}^{n} E\left[\lambda_{i}\right] C_{i}\left(\frac{D}{Q}\right)=\sum_{i=1}^{n} D E\left[\lambda_{i}\right] C_{i} .
$$

\subsubsection{Inventory holding cost for reworked items ( $\left.\mathrm{IHC}_{2}\right)$}

Maximum Inventory can be calculated by $h=(P-D) E\left(\lambda_{i}\right)\left(\frac{Q}{P}\right)$. The contemporaneous consumption and reworking time in the first stage inspection is $t_{p}=E\left(\lambda_{i}\right)\left(\frac{Q}{P}\right)$ and the pure consumption time in the first stage inspection $t_{d}=h / D=(P-D) E\left(\lambda_{i}\right) Q / P D$. Therefore, total reworking and consumption time is $t_{p}+t_{d}=$ $E\left(\lambda_{i}\right)(Q / P)+(P-D) E\left(\lambda_{i}\right) Q / P D=E\left(\lambda_{i}\right) Q / D$. Total Inventory for each phase and the average total inventory over the $Q / D$ period can be obtained as

$$
\begin{aligned}
\text { Inventory }_{i} & =\frac{\frac{1}{2}\left(1-\frac{D}{P}\right) Q^{2}\left(E\left(\lambda_{i}\right)\right)^{2}}{D} \\
\text { Inventory } & =\frac{1}{n}\left(\text { Inventory }_{1}+\text { Inventory }_{2}+\ldots+\text { Inventory }_{n}\right)=\frac{1}{2 n}\left(1-\frac{D}{P}\right) Q \sum_{i=1}^{n}\left(E\left(\lambda_{i}\right)\right)^{2} .
\end{aligned}
$$

Therefore, inventory holding cost for reworked items should be calculated multiplying by $H$, carrying cost per unit inventory.

$$
\mathrm{IHC}_{2}=\frac{H}{2 n}\left(1-\frac{D}{P}\right) Q \sum_{i=1}^{n}\left(E\left[\lambda_{i}\right]\right)^{2} .
$$

\subsubsection{Total revenue (TR)}

Annual total revenue can be calculated by multiplying per cycle demand $D$ and unit selling price per unit $V$. Annual demand $D$ can be expressed as $\alpha / V^{\beta}$. The revenue per cycle is

$$
\mathrm{TR}=V \times \frac{\alpha}{V^{\beta}} .
$$

\subsubsection{Total profit (TP)}

Therefore, the expected total profit $\operatorname{TP}\left(Q, I_{i}, V\right)$ for the whole MPMS is calculated by subtracting all costs from the total sales in terms of inequality budget constraint. To calculate the decision variables' values that 
maximize the total profit of a non-linear programming problem with inequality constraint, the KKT optimization method is applied.

$$
\begin{aligned}
\operatorname{TP}\left(Q, I_{i}, V\right)= & V \times \frac{\alpha}{V^{\beta}}-\left(\frac{1}{Q} \sum_{i=1}^{n} D F_{i}\left(I_{i}\right)+\sum_{i=1}^{n} D C_{i}+\sum_{i=1}^{n} S 1_{i} D+\sum_{i=1}^{n} S 2_{i} E\left[\lambda_{i}\right] D\right. \\
& +\frac{H Q}{2 n P}\left[\sum_{i=1}^{n}\left(P\left(1-E\left[\lambda_{i}\right]\right)-D\right) \prod_{j=1}^{i}\left(1-E\left[\lambda_{j-1}\right]\right)\right] \\
& \left.+\sum_{i=1}^{n} D E\left[\lambda_{i}\right] C_{i}+\frac{H}{2 n}\left(1-\frac{D}{P}\right) Q \sum_{i=1}^{n}\left(E\left[\lambda_{i}\right]\right)^{2}+\sum_{i=1}^{n} I_{i}\right)
\end{aligned}
$$

subject to $I-\sum_{i=1}^{n} I_{i} \geq 0, Q, I_{i}, V \geq 0$ for all $i$.

\subsection{Solution methodology}

The optimization model is a non-linear programming problem with an inequality constraint with decision variables $Q, I_{i}$, and $V$. KKT method would be the best method to obtain the optimum profit. The global optimum is proved through the Hessian matrix with a solution that has a closed/quasi-closed form, $\mu$, which is used as the parameter of inequality constraint in the KKT method since parameter $\lambda$ is already used as the proportion of defective items.

$$
\begin{aligned}
& \operatorname{TP}\left(Q, I_{i}, V\right)+\mu_{1}\left(I-\sum_{i=1}^{n} I_{i}\right)=0 \\
& \frac{\partial \mathrm{TP}\left(Q, I_{i}, V\right)}{\partial Q}=\frac{\sum_{i=1}^{n} V^{-\beta} \alpha\left(b L_{i}+e^{-a I_{i}}\left(-b L_{i}+U_{i}\right)\right)}{Q^{2}}-\frac{1}{2 n P} H \sum_{i=1}^{n}\left(1-\lambda_{i}\right) \\
& \quad \times\left(-V^{-\beta} \alpha+P\left(1-\lambda_{i}\right)\right)\left(1-\lambda_{i}\right)-\frac{H\left(1-\frac{V^{-\beta} \alpha}{P}\right) \sum_{i=1}^{n} \lambda_{i}^{2}}{2 n}=0 \\
& \frac{\partial \mathrm{TP}\left(Q, I_{i}, V\right)}{\partial I_{i}}=0=-\left(1+\mu_{1}\right)-\left\{\begin{array}{l}
1-\mathrm{Ceiling}_{i}+\mathrm{Floor}_{i} \operatorname{Re}_{i} \geq 1 \& \& n-\operatorname{Re}_{i} \geq 0 \& \& \operatorname{Im}_{i}=0 \\
0
\end{array}\right. \\
& \frac{\partial \mathrm{TP}\left(Q, I_{i}, V\right)}{\partial V}=V^{-\beta} \alpha(1-\beta)-\sum_{i=1}^{n}-V^{-1-\beta} \alpha \beta C_{i}-\sum_{i=1}^{n}-V^{-1-\beta} \alpha \beta S 1_{i} \\
& \quad-\frac{\sum_{i=1}^{n}-V^{-1-\beta} \alpha \beta\left(b L_{i}+e^{-a I_{i}}\left(-b L_{i}+U_{i}\right)\right)}{Q}-\frac{H Q \sum_{i=1}^{n} V^{-1-\beta} \alpha \beta\left(1-\lambda_{i}\right)}{2 n P} \\
& \quad-\sum_{i=1}^{n}-V^{-1-\beta} \alpha \beta \mathrm{C}_{\mathrm{i}} \lambda_{i}-\sum_{i=1}^{n}-V^{-1-\beta} \alpha \beta \mathrm{S}_{i} \lambda_{i}-\frac{H Q V^{-1-\beta} \alpha \beta \sum_{i=1}^{n} \lambda_{i}^{2}}{2 n P}=0 \\
& \mu_{1}\left(I-\sum_{i=1}^{n} I_{i}\right)=0 \\
& \operatorname{complementary~slackness} \\
& Q, I_{i}, V, \mu_{1} \geq 0 .
\end{aligned}
$$

The optimum values of decision variables can be obtained from equations (4.1)-(4.3). 
By using sufficient optimality conditions, the optimum decision variables can be proved as global optimum. To calculate the principal minors of the Hessian Matrix, the second-order derivatives are given below.

$$
\begin{aligned}
& \frac{\partial^{2} \mathrm{TP}}{\partial Q^{2}}=-\frac{2 \sum_{i=1}^{n} V^{-\beta} \alpha\left(b L_{i}+e^{-a I_{i}}\left(-b L_{i}+U_{i}\right)\right)}{Q^{3}} \\
& \frac{\partial^{2} \mathrm{TP}}{\partial Q \partial I_{i}}=\frac{\sum_{j=1}^{n}-a e^{-a I_{j}} V^{-\beta} \alpha \delta_{i, j}\left(-b L_{j}+U_{j}\right)}{Q^{2}} \\
& \frac{\partial^{2} \mathrm{TP}}{\partial V^{2}}=\frac{\sum_{i=1}^{n}-V^{-1-\beta} \alpha \beta\left(b L_{i}+e^{-a I_{i}}\left(-b L_{i}+U_{i}\right)\right)}{Q^{2}}-\frac{H \sum_{i=1}^{n} V^{-1-\beta} \alpha \beta\left(1-\lambda_{i}\right)}{2 n P}-\frac{H V^{-1-\beta} \alpha \beta \sum_{i=1}^{n} \lambda_{i}^{2}}{2 n P} \\
& \frac{\partial^{2} \mathrm{TP}}{\partial Q \partial I_{i}}=\frac{\sum_{j=1}^{n}-a e^{-a I_{j}} V^{-\beta} \alpha \delta_{i, j}\left(-b L_{j}+U_{j}\right)}{Q^{2}} \\
& \frac{\partial^{2} \mathrm{TP}}{\partial Q \partial V}=-\frac{\sum_{j=1}^{n} a^{2} e^{-a I_{j}} V^{-\beta} \alpha \delta_{i, j}^{2}\left(-b L_{j}+U_{j}\right)}{Q} \\
& \frac{\partial^{2} \mathrm{TP}}{\partial I_{i} \partial Q}=-\frac{\sum_{j=1}^{n} a e^{-a I_{j}} V^{-1-\beta} \alpha \beta \delta_{i, j}\left(-b L_{j}+U_{j}\right)}{Q} \\
& \frac{\partial^{2} \mathrm{TP}}{\partial I_{i}^{2}}=\frac{\sum_{i=1}^{n}-V^{-1-\beta} \alpha \beta\left(b L_{i}+e^{-a I_{i}}\left(-b L_{i}+U_{i}\right)\right)}{Q^{2}}-\frac{H \sum_{i=1}^{n} V^{-1-\beta} \alpha \beta\left(1-\lambda_{i}\right)}{2 n P}-\frac{H V^{-1-\beta} \alpha \beta \sum_{i=1}^{n} \lambda_{i}^{2}}{2 n P} \\
& \frac{\partial^{2} \mathrm{TP}}{\partial I_{i}^{2}}=-\frac{\sum_{j=1}^{n} a e^{-a I_{j}} V^{-1-\beta} \alpha \beta \delta_{i, j}\left(-b L_{j}+U_{j}\right)}{Q} \\
& \frac{\partial^{2} \mathrm{TP}}{\partial V \partial Q}=-V^{-1-\beta} \alpha(1-\beta) \beta-\sum_{i=1}^{n}-\alpha \beta\left(-V^{-2-\beta}-V^{-2-\beta} \beta\right) C_{i}-\sum_{i=1}^{n}-\alpha \beta\left(-V^{-2-\beta}-V^{-2-\beta} \beta\right) S 1_{i} \\
& -\frac{\sum_{i=1}^{n}-\alpha \beta\left(-V^{-2-\beta}-V^{-2-\beta} \beta\right)\left(b L_{i}+e^{-a I_{i}}\left(-b L_{i}+U_{i}\right)\right)}{Q} \\
& -\frac{1}{2 n P} H Q \sum_{i=1}^{n} \alpha \beta\left(-V^{-2-\beta}-V^{-2-\beta} \beta\right)\left(1-\lambda_{i}\right)-\sum_{i=1}^{n}-\alpha \beta\left(-V^{-2-\beta}-V^{-2-\beta} \beta\right) C_{i} \lambda_{i} \\
& -\sum_{i=1}^{n}-\alpha \beta\left(-V^{-2-\beta}-V^{-2-\beta} \beta\right) S 2_{i} \lambda_{i}-\frac{H Q V^{-2-\beta} \alpha(-1-\beta) \beta \sum_{i=1}^{n} \lambda_{i}^{2}}{2 n P} \\
& \frac{\partial^{2} \mathrm{TP}}{\partial V \partial I_{i}}=-\frac{\sum_{j=1}^{n} a e^{-a I_{j}} V^{-1-\beta} \alpha \beta \delta_{i, j}\left(-b L_{j}+U_{j}\right)}{Q} \\
& \frac{\partial^{2} \mathrm{TP}}{\partial V^{2}}=-V^{-1-\beta} \alpha(1-\beta) \beta-\sum_{i=1}^{n}-\alpha \beta\left(-V^{-2-\beta}-V^{-2-\beta} \beta\right) C_{i}-\sum_{i=1}^{n}-\alpha \beta\left(-V^{-2-\beta}-V^{-2-\beta} \beta\right) S 1_{i} \\
& -\frac{\sum_{i=1}^{n}-\alpha \beta\left(-V^{-2-\beta}-V^{-2-\beta} \beta\right)\left(b L_{i}+e^{-a I_{i}}\left(-b L_{i}+U_{i}\right)\right)}{Q} \\
& -\frac{1}{2 n P} H Q \sum_{i=1}^{n} \alpha \beta\left(-V^{-2-\beta}-V^{-2-\beta} \beta\right)\left(1-\lambda_{i}\right)-\sum_{i=1}^{n}-\alpha \beta\left(-V^{-2-\beta}-V^{-2-\beta} \beta\right) C_{i} \lambda_{i} \\
& -\sum_{i=1}^{n}-\alpha \beta\left(-V^{-2-\beta}-V^{-2-\beta} \beta\right) S 2_{i} \lambda_{i}-\frac{H Q V^{-2-\beta} \alpha(-1-\beta) \beta \sum_{i=1}^{n} \lambda_{i}^{2}}{2 n P} .
\end{aligned}
$$

The first principal minor is

$$
\frac{\partial^{2} \mathrm{TP}}{\partial Q^{2}}=-\frac{2 \sum_{i=1}^{n} V^{-\beta} \alpha\left(b L_{i}+e^{-a I_{i}}\left(-b L_{i}+U_{i}\right)\right)}{Q^{3}}<0 .
$$


The second principal minor is

$$
\begin{aligned}
\left(\begin{array}{cc}
\frac{\partial^{2} \mathrm{TP}}{\partial Q^{2}} & \frac{\partial^{2} \mathrm{TP}}{\partial Q \partial I_{i}} \\
\frac{\partial^{2} \mathrm{TP}}{\partial Q \partial I_{i}} & \frac{\partial^{2} \mathrm{TP}}{\partial I_{i}^{2}}
\end{array}\right)= & \left\{\left\{-\frac{2 \sum_{i=1}^{n} V^{-\beta} \alpha\left(b L_{i}+e^{-a I_{i}}\left(-b L_{i}+U_{i}\right)\right)}{Q^{3}}, \frac{\sum_{j=1}^{n}-a e^{-a I_{j}} V^{-\beta} \alpha \delta_{i, j}\left(-b L_{j}+U_{j}\right)}{Q^{2}}\right\},\right. \\
& \left.\left\{\frac{\sum_{j=1}^{n}-a e^{-a I_{j}} V^{-\beta} \alpha \delta_{i, j}\left(-b L_{j}+U_{j}\right)}{Q^{2}},-\frac{\sum_{j=1}^{n} a^{2} e^{-a I_{j}} V^{-\beta} \alpha \delta_{i, j}^{2}\left(-b L_{j}+U_{j}\right)}{Q}\right\}\right\} \\
D 2= & \operatorname{Det}\left(\left(\begin{array}{ll}
\frac{\partial \mathrm{TP}}{\partial Q^{2}} & \frac{\partial \mathrm{TP}}{\partial Q \partial I_{i}} \\
\frac{\partial \mathrm{TP}}{\partial Q \partial I_{i}} & \frac{\partial \mathrm{TP}}{\partial I_{i}^{2}}
\end{array}\right)\right)=\frac{1}{Q^{4}}\left(\left(\sum_{j=1}^{n} a e^{-a I_{j}} V^{-\beta} \alpha \delta_{i, j}\left(-b L_{j}+U_{j}\right)\right)^{2}\right. \\
& \left.+2\left(\sum_{i=1}^{n} V^{-\beta} \alpha\left(b L_{i}+e^{-a I_{i}}\left(-b L_{i}+U_{i}\right)\right)\right) \sum_{j=1}^{n} a^{2} e^{-a I_{j}} V^{-\beta} \alpha \delta_{i, j}^{2}\left(b L_{j}-U_{j}\right)\right)>0 .
\end{aligned}
$$

The third principal minor is

$$
\begin{aligned}
& \left(\begin{array}{lll}
\frac{\partial^{2} \mathrm{TP}}{\partial Q^{2}} & \frac{\partial^{2} \mathrm{TP}}{\partial Q \partial I_{i}} & \frac{\partial^{2} \mathrm{TP}}{\partial Q \partial V} \\
\frac{\partial^{2} \mathrm{TP}}{\partial I_{i} \partial Q} & \frac{\partial^{2} \mathrm{TP}}{\partial I_{i}^{2}} & \frac{\partial^{2} \mathrm{TP}}{\partial I_{i} \partial V} \\
\frac{\partial^{2} \mathrm{TP}}{\partial V \partial Q} & \frac{\partial^{2} \mathrm{TP}}{\partial V \partial I_{i}} & \frac{\partial^{2} \mathrm{TP}}{\partial V^{2}}
\end{array}\right)=\left\{\left\{-\frac{2 \sum_{i=1}^{n} V^{-\beta} \alpha\left(b L_{i}+e^{-a I_{i}}\left(-b L_{i}+U_{i}\right)\right)}{Q^{3}},\right.\right. \\
& \frac{\sum_{j=1}^{n}-a e^{-a I_{j}} V^{-\beta} \alpha \delta_{i, j}\left(-b L_{j}+U_{j}\right)}{Q^{2}}, \frac{\sum_{i=1}^{n}-V^{-1-\beta} \alpha \beta\left(b L_{i}+e^{-a I_{i}}\left(-b L_{i}+U_{i}\right)\right)}{Q^{2}} \\
& \left.-\frac{H \sum_{i=1}^{n} V^{-1-\beta} \alpha \beta\left(1-\lambda_{i}\right)}{2 n P}-\frac{H V^{-1-\beta} \alpha \beta \sum_{i=1}^{n} \lambda_{i}^{2}}{2 n P}\right\}, \\
& \left\{\frac{\sum_{j=1}^{n}-a e^{-a I_{j}} V^{-\beta} \alpha \delta_{i, j}\left(-b L_{j}+U_{j}\right)}{Q^{2}},-\frac{\sum_{j=1}^{n} a^{2} e^{-a I_{j}} V^{-\beta} \alpha \delta_{i, j}^{2}\left(-b L_{j}+U_{j}\right)}{Q},\right. \\
& \left.-\frac{\sum_{j=1}^{n} a e^{-a I_{j}} V^{-1-\beta} \alpha \beta \delta_{i, j}\left(-b L_{j}+U_{j}\right)}{Q}\right\} \text {, } \\
& \left\{\frac{\sum_{i=1}^{n}-V^{-1-\beta} \alpha \beta\left(b L_{i}+e^{-a I_{i}}\left(-b L_{i}+U_{i}\right)\right)}{Q^{2}}-\frac{H \sum_{i=1}^{n} V^{-1-\beta} \alpha \beta\left(1-\lambda_{i}\right)}{2 n P}\right. \\
& -\frac{H V^{-1-\beta} \alpha \beta \sum_{i=1}^{n} \lambda_{i}^{2}}{2 n P},-\frac{\sum_{j=1}^{n} a e^{-a I_{j}} V^{-1-\beta} \alpha \beta \delta_{i, j}\left(-b L_{j}+U_{j}\right)}{Q}, \\
& -V^{-1-\beta} \alpha(1-\beta) \beta-\sum_{i=1}^{n}-\alpha \beta\left(-V^{-2-\beta}-V^{-2-\beta} \beta\right) C_{i} \\
& -\sum_{i=1}^{n}-\alpha \beta\left(-V^{-2-\beta}-V^{-2-\beta} \beta\right) S 1_{i} \\
& -\frac{1}{Q}\left(\sum_{i=1}^{n}-\alpha \beta\left(-V^{-2-\beta}-V^{-2-\beta} \beta\right)\left(b L_{i}+e^{-a I_{i}}\left(-b L_{i}+U_{i}\right)\right)\right)-\frac{1}{2 n P} H Q \\
& \times \sum_{i=1}^{n} \alpha \beta\left(-V^{-2-\beta}-V^{-2-\beta} \beta\right)(1-\lambda[i])-\sum_{i=1}^{n}-\alpha \beta\left(-V^{-2-\beta}-V^{-2-\beta} \beta\right) C_{i} \lambda_{i}
\end{aligned}
$$


CONTROLLING DEFECTIVE ITEMS IN A COMPLEX MPMS

$$
\left.\left.-\sum_{i=1}^{n}-\alpha \beta\left(-V^{-2-\beta}-V^{-2-\beta} \beta\right) S 2_{i} \lambda_{i}-\frac{H Q V^{-2-\beta} \alpha(-1-\beta) \beta \sum_{i=1}^{n} \lambda_{i}^{2}}{2 n P}\right\}\right\}
$$

$$
\begin{aligned}
& D 3=\operatorname{Det}\left(\left(\begin{array}{ccc}
\frac{\partial^{2} \mathrm{TP}}{\partial Q^{2}} & \frac{\partial^{2} \mathrm{TP}}{\partial Q \partial I_{i}} & \frac{\partial^{2} \mathrm{TP}}{\partial Q \partial V} \\
\frac{\partial^{2} \mathrm{TP}}{\partial I_{i} \partial Q} & \frac{\partial^{2} \mathrm{TP}}{\partial I_{i}^{2}} & \frac{\partial^{2} \mathrm{TP}}{\partial I_{i} \partial V} \\
\frac{\partial^{2} \mathrm{TP}}{\partial V \partial Q} & \frac{\partial^{2} \mathrm{TP}}{\partial V \partial I_{i}} & \frac{\partial^{2} \mathrm{TP}}{\partial V^{2}}
\end{array}\right)\right)=-\frac{1}{4 n^{2} P^{2} Q^{5}} V^{-2(1+\beta)} \\
& \times\left(2 n P V^{1+\beta}\left(\sum_{j=1}^{n} a e^{-a I_{j}} V^{-1-\beta} \alpha \beta \delta_{i, j}\left(-b L_{j}+U_{j}\right)\right)\right. \\
& \times\left(2 n P V^{1+\beta}\left(\sum_{i=1}^{n}-V^{-1-\beta} \alpha \beta\left(b L_{i}+e^{-a I_{i}}\left(-b L_{i}+U_{i}\right)\right)\right) \sum_{j=1}^{n}-a e^{-a I_{j}} V^{-\beta} \alpha \delta_{i, j}\left(-b L_{j}+U_{j}\right)\right. \\
& +4 n P V^{1+\beta}\left(\sum_{i=1}^{n} V^{-\beta} \alpha\left(b L_{i}+e^{-a I_{i}}\left(-b L_{i}+U_{i}\right)\right)\right) \sum_{j=1}^{n} a e^{-a I_{j}} V^{-1-\beta} \alpha \beta \delta_{i, j}\left(-b L_{j}+U_{j}\right) \\
& \left.+H Q^{2}\left(\sum_{j=1}^{n}-a e^{-a I_{j}} V^{-\beta} \alpha \delta_{i, j}\left(-b L_{j}+U_{j}\right)\right)\left(V^{1+\beta} \sum_{i=1}^{n} V^{-1-\beta} \alpha \beta\left(1-\lambda_{i}\right)+\alpha \beta \sum_{i=1}^{n} \lambda_{i}^{2}\right)\right) \\
& +2 n P V^{\beta}\left(\left(\sum_{j=1}^{n}-a e^{-a I_{j}} V^{-\beta} \alpha \delta_{i, j}\left(-b L_{j}+U_{j}\right)\right)^{2}-2\left(\sum_{i=1}^{n} V^{-\beta} \alpha\left(b L_{i}+e^{-a I_{i}}\left(-b L_{i}+U_{i}\right)\right)\right)\right. \\
& \left.\times \sum_{j=1}^{n} a^{2} e^{-a I_{j}} V^{-\beta} \alpha \delta_{i, j}^{2}\left(-b L_{j}+U_{j}\right)\right)\left(V ^ { 2 + \beta } \left(2 n P Q \sum_{i=1}^{n}-\alpha \beta\left(-V^{-2-\beta}-V^{-2-\beta} \beta\right) C_{i}\right.\right. \\
& +2 n P Q \sum_{i=1}^{n}-\alpha \beta\left(-V^{-2-\beta}-V^{-2-\beta} \beta\right) S 1_{i}+H Q^{2} \sum_{i=1}^{n} \alpha \beta\left(-V^{-2-\beta}-V^{-2-\beta} \beta\right)\left(1-\lambda_{i}\right) \\
& +2 n P\left(\sum_{i=1}^{n}-\alpha \beta\left(-V^{-2-\beta}-V^{-2-\beta} \beta\right)\left(b L_{i}+e^{-a I_{i}}\left(-b L_{i}+U_{i}\right)\right)\right. \\
& \left.\left.+Q\left(\sum_{i=1}^{n}-\alpha \beta\left(-V^{-2-\beta}-V^{-2-\beta} \beta\right) C_{i} \lambda_{i}+\sum_{i=1}^{n}-\alpha \beta\left(-V^{-2-\beta}-V^{-2-\beta} \beta\right) S 2_{i} \lambda_{i}\right)\right)\right) \\
& \left.-Q \alpha \beta\left(2 n P V(-1+\beta)-H Q(1+\beta) \sum_{i=1}^{n} \lambda_{i}^{2}\right)\right)+\left(2 n P V^{1+\beta} \sum_{i=1}^{n}-V^{-1-\beta} \alpha \beta\left(b L_{i}+e^{-a I_{i}}\left(-b L_{i}+U_{i}\right)\right)\right. \\
& \left.-H Q^{2}\left(V^{1+\beta} \sum_{i=1}^{n} V^{-1-\beta} \alpha \beta\left(1-\lambda_{i}\right)+\alpha \beta \sum_{i=1}^{n} \lambda_{i}^{2}\right)\right)\left(-2 n P V^{1+\beta}\left(\sum_{j=1}^{n}-a e^{-a I_{j}} V^{-\beta} \alpha \delta_{i, j}\left(-b L_{j}+U_{j}\right)\right)\right. \\
& \times \sum_{j=1}^{n} a e^{-a I_{j}} V^{-1-\beta} \alpha \beta \delta_{i, j}\left(-b L_{j}+U_{j}\right)+\left(\sum_{j=1}^{n} a^{2} e^{-a I_{j}} V^{-\beta} \alpha \delta_{i, j}^{2}\left(-b L_{j}+U_{j}\right)\right) \\
& \times\left(2 n P V^{1+\beta} \sum_{i=1}^{n}-V^{-1-\beta} \alpha \beta\left(b L_{i}+e^{-a I_{i}}\left(-b L_{i}+U_{i}\right)\right)\right.
\end{aligned}
$$



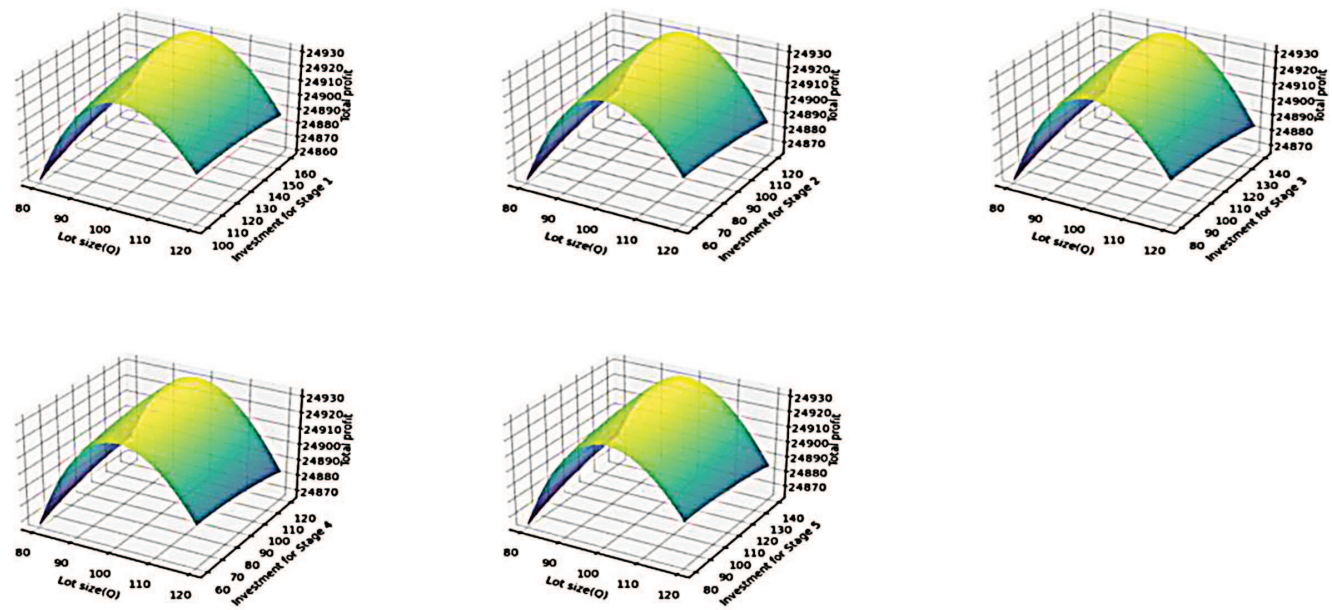

Figure 2. Total profit versus lot size $Q$ and investment for phase $i(i=1 \sim 5)$.

$$
\left.\left.\left.-H Q^{2}\left(V^{1+\beta} \sum_{i=1}^{n} V^{-1-\beta} \alpha \beta\left(1-\lambda_{i}\right)+\alpha \beta \sum_{i=1}^{n} \lambda_{i}^{2}\right)\right)\right)\right)<0 .
$$

Thus, the global optimality is proved. Now, to prove the proposed model's validity, numerical experiments are done, which are given in the next section.

\section{NUMERICAL EXPERIMENTS}

The optimization problem has the global minimum value if the Hessian matrix's principal minors have alternating signs. An optimization problem with decision variables $Q, I_{i}, V$ has three principal minors, and it is found that these are alternating in signs. Therefore, the optimization problem has a global minimum.

Since there are considerable numbers of decision variables, a numerical example is introduced instead of calculating the optimal decision values.

\subsection{Numerical examples}

Two numerical examples are given to prove the validity of the model. The data for Example 5.1 are taken from Sarker et al. [30], and for Example 5.2, the industry data are handled. Both examples assume a uniform distribution of defective rates, and defective items are reworked in the same cycle.

Example 5.1. The input data for the numerical example are given below. In this example, the production system is considered as $i=5$, the parametric values for each phase are taken as $P=420$ units/year, $H=\$ 50 /$ unit $/$ year, $D=252.86$ units $/$ year, $b=\$ 100 /$ hour, $L_{i}=0.167 \mathrm{~h}, S 2_{i}=\$ 0.02 /$ item, $\alpha=56000$, $\beta=1.5$. At different phases, the other parametric values are taken as $U_{i}=(250,200,215,195,220)$, $S 2_{i}=\$(0.02,0.03,0.025,0.02,0.01) /$ item, $F_{i}=\$\left(16.7+U_{1} e^{-0.005 I_{1}}-16.7 e^{-0.005 I_{1}}, 16.7+U_{2} e^{-0.005 I_{2}}-\right.$ $16.7 e^{-0.005 I_{2}}, 16.7+U_{3} e^{-0.005 I_{3}}-16.7 e^{-0.005 I_{3}}, 16.7+U_{4} e^{-0.005 I_{4}}-16.7 e^{-0.005 I_{4}}, 16.7+U_{5} e^{-0.005 I_{5}}-$ $\left.16.7 e^{-0.005 I_{5}}\right) /$ phase, $C_{i}=\$(10,12,18,9,25) /$ unit. The random defective rate follows a uniform distribution. The range of the uniform distribution is $[0.008,0.012]$. Thus, $E\left[\lambda_{i}\right]=\frac{0.008+0.012}{2}=0.01$.

The optimum results of the decision variables are $Q=99.18$ units, $I_{i}=\$(144.43,96.15,111.91,90.62,116.88) /$ cycle, $V=\$ 45.95 /$ unit. The maximum profit of the MPMS is $\$ 24932.57 /$ year.

Graphs of the total cost versus lot size, investment per phase, and selling price are given in Figures 2 and 3. 


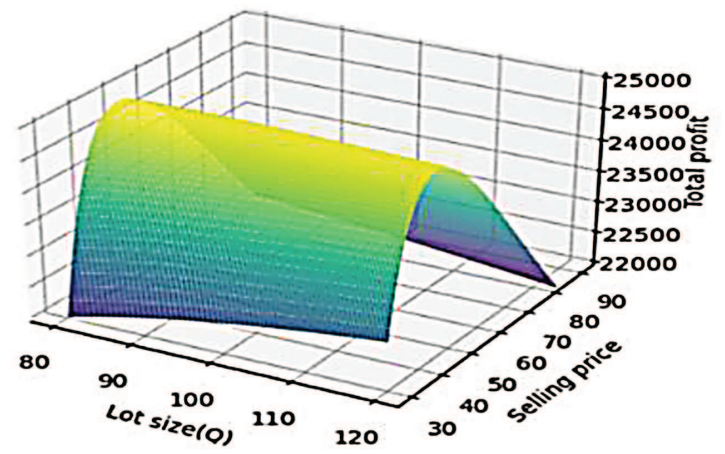

Figure 3. Total profit versus lot size $Q$ and selling price.

TABLE 2. Sensitivity analysis for crucial parameters.

\begin{tabular}{lllllllll}
\hline & \multicolumn{3}{c}{ Total profit } & \multicolumn{5}{c}{ Selling price } \\
\cline { 2 - 9 } & $-50 \%$ & $-25 \%$ & $25 \%$ & $50 \%$ & $-50 \%$ & $-25 \%$ & $25 \%$ & $50 \%$ \\
\hline$H$ & 3.095 & 1.314 & -1.116 & -2.123 & -0.294 & -0.140 & 0.340 & 0.665 \\
$U_{i}$ & 3.087 & 1.271 & -1.058 & -2.017 & -0.263 & -0.058 & 0.322 & 0.630 \\
$S 1_{i}$ & 0.038 & 0.019 & -0.019 & -0.038 & -0.085 & -0.043 & 0.042 & 0.085 \\
$S 2_{i}$ & 0.0003 & 0.0001 & -0.0001 & -0.0003 & -0.001 & -0.0002 & 0.0001 & 0.001 \\
$\lambda$ & 0.263 & 0.131 & -0.13 & -0.259 & -0.668 & -0.335 & 0.331 & 0.663 \\
$C_{1}$ & 3.885 & 1.879 & -1.737 & -3.435 & -8.363 & -4.130 & 4.053 & 8.046 \\
$C_{2}$ & 4.728 & 2.27 & -2.108 & -4.076 & -10.094 & -4.967 & 4.856 & 9.629 \\
$C_{3}$ & 7.411 & 3.473 & -3.109 & -5.920 & -15.472 & -7.507 & 7.251 & 14.387 \\
$C_{4}$ & 3.473 & 1.686 & -1.595 & -3.109 & -7.507 & -3.712 & 3.650 & 7.251 \\
$C_{5}$ & 10.901 & 4.942 & -4.235 & -7.931 & -22.369 & -10.531 & 10.024 & 19.915 \\
\hline
\end{tabular}

Example 5.2. The modified data of the industry are used for the case study. Demand for both examples is considered as same. The data and optimum results are given below.

$i=5, P=1000$ units/year, $H=\$ 40 /$ unit/year, $D=252.86$ units/year, $b=\$ 100 /$ hour, $L_{i}=0.167 \mathrm{~h}$, $S 2_{i}=\$ 0.02 /$ item $\alpha=56000, \beta=1.5$. At different phases, the other parametric values are taken as $U_{i}=(190,180,205,195,220), S 2_{i}=\$ 0.02 /$ item, $F_{i}=\$\left(16.7+U_{1} e^{-0.005 I_{1}}-16.7 e^{-0.005 I_{1}}, 16.7+\right.$ $U_{2} e^{-0.005 I_{2}}-16.7 e^{-0.005 I_{2}}, 16.7+U_{3} e^{-0.005 I_{3}}-16.7 e^{-0.005 I_{3}}, 16.7+U_{4} e^{-0.005 I_{4}}-16.7 e^{-0.005 I_{4}}, 16.7+U_{5} e^{-0.005 I_{5}}-$ $\left.16.7 e^{-0.005 I_{5}}\right) /$ phase, $C_{i}=\$ 10 /$ unit. The random defective rate follows a uniform distribution. The range of the uniform distribution is $[0.008,0.012]$. Thus, $E\left[\lambda_{i}\right]=\frac{0.12+0.18}{2}=0.15$.

The optimum results of the decision variables are $Q=105.94$ units, $I_{i}=$ $\$(145.26,133.5,162.02,150.96,156.54) /$ cycle, $\quad V=\$ 36.61 /$ unit. The maximum profit of the MPMS is $\$ 28564.04 /$ year.

\subsection{Sensitivity analysis}

Sensitivity analysis for crucial parameters is obtained in Tables 2 and 3.

It is found that annual fractional cost $\alpha$ and price elasticity parameter $\beta$ are very sensitive parameters. Total profit decreases $20 \%$ with $20 \%$ decreasing the elasticity parameter $\alpha$.

The selling price has been changed about $3 \%$ in the positive and negative direction with $20 \%$ changes on both sides. With the changes of $20 \%$ of $\beta$ in the negative and positive direction, profit changes about $269 \%$ in the negative direction and $72 \%$ in a positive direction but selling price changes total $103 \%$ in both directions. 
TABLE 3. Sensitivity analysis for $\alpha, \beta$.

\begin{tabular}{lllllllll}
\hline & \multicolumn{4}{c}{ Total profit } & \multicolumn{4}{c}{ Selling price } \\
\cline { 2 - 9 } & $-20 \%$ & $-10 \%$ & $10 \%$ & $20 \%$ & $-20 \%$ & $-10 \%$ & $10 \%$ & $20 \%$ \\
\hline$\alpha$ & -21.911 & -11.001 & 11.09 & 22.272 & 3.449 & 1.613 & -1.608 & -3.286 \\
$\beta$ & 269.091 & 89.419 & -47.102 & -72.518 & 87.723 & 23.037 & -11.322 & -16.014 \\
\hline
\end{tabular}

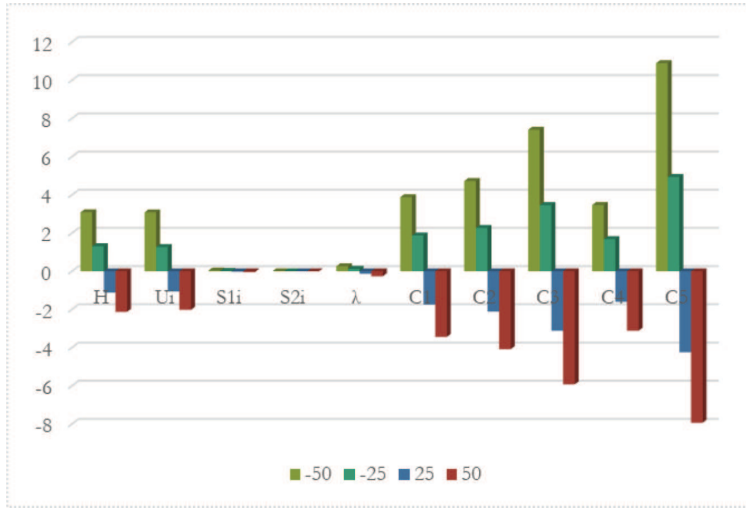

FiguRE 4. Changes of profit concerning cost parameters.

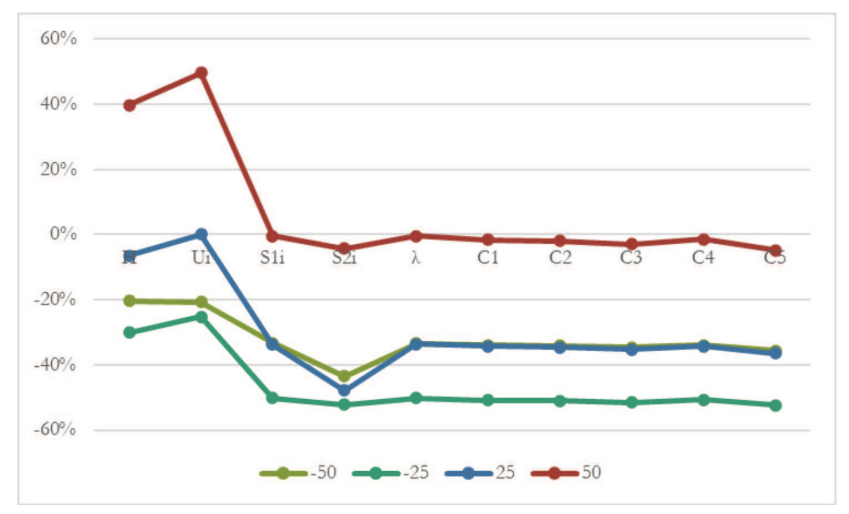

Figure 5. Changes of selling-price concerning cost parameters.

The next sensitiveness of parameter is the processing cost of 2 nd phase of the production system. The processing cost for 3rd phase is the next sensitive parameter. Table 2 and Figure 4 shows that the processing cost for phase 5 is most sensitive among all cost parameters. Holding cost and maximum limit of setup cost are almost the same sensitivity.

- Changing processing cost affects most on changing the selling price of products (see Fig. 5). The selling price decreases with the decreasing of processing cost and vice versa. The greater change happens at phase 5 .

\subsection{Managerial insights}

Some insights from the study can be drawn for the multi-stage production industry. 
- Setup cost plays a very important role for MPMS. The setup cost reduction is necessary to gain more profit. Thus, the investment to reduce setup cost is an important step the industry should follow.

- Processing cost is the most sensitive cost parameter for this study. Thus, the industry should take care of the processing cost at each stage of the production system.

- To reduce waste as imperfect product reworking process can be adopted by industries. Thus, fewer defective products will be disposed of from the system. The industry can sell a greater number of products and can gain more.

\section{Conclusions And Future extensions}

The study proved that the reworking process could reduce the waste from the MPMS. Investments to reduce setup costs were applied in MPMS, increasing the system's profit. A discrete investment function was introduced with an inequality constraint in that all investment budgets might not be allocated due to the trade-off between costs. The demand of the MPMS was considered as selling price dependent. The profit of the MPMS was maximized, and it was the global maximum profit. However, the proposed model can help manufacturing companies make the best decision to maximize profit. Attempts to find selling price demand and optimal investment policy, and optimal batch size were made in this research under the MPMS using two given data. For solving the non-linear optimization model with an inequality constraint, a KKT method was implemented, and one numerical experiment and one case study were conducted. As shown in sensitivity analysis, alpha and beta are very sensitive parameters. Thus, they should be appropriately tuned. The first numerical example allocated all investment budgets, but the second one did not give all investment budgets. Therefore, the maximum profit can be obtained without allocating all investment budgets to decrease setup costs. The numerical example in this research was based on uniform distribution defective rate, but it would be better if other random distributions were introduced for a more generalized approach. Carefully examining their current production rate of random defective items and deciding which distribution pattern suits the most, industry managers can pick a specific model for their manufacturing system, enabling them to calculate the system's global maximum profit.

The research considered a constant production rate for the MPMS, which is one of the limitations of this study. The study can be extended by applying autonomation policy and smart production process for the manufacturing system [7]. Lead time is an important factor for the manufacturer. The lower lead time increases the demand for a product, which is another limitation of this study. Thus, controllable lead time [6] can extend this research. The quality of the product was not counted for both perfect and reworked products. The production system can consider reworked products' quality improvement [39]. Owing to random defective rates and remanufacturing shortages may arise. Those shortages may be partially or fully backordered using remanufactured products [29], which can be considered as an extended idea of this research.

Acknowledgements. The work is supported by the National Research Foundation of Korea (NRF) grant, funded by the Korea Government (MSIT) (NRF-2020R1F1A1064460).

\section{REFERENCES}

[1] W. Ahmed, M. Moazzam, B. Sarkar and S.U. Rehman, Synergic effect of reworking for imperfect quality items with the integration of multi-period delay-in-payment and partial backordering in global supply chains. Engineering 7 (2021) $260-271$.

[2] H.K. Alfares and A.M. Ghaithan, Inventory and pricing model with price-dependent demand, time-varying holding cost, and quantity discounts. Comp. Ind. Engin. 94 (2016) 170-177.

[3] K. Biel and C.H. Glock, Governing the dynamics of multi-stage production systems subject to learning and forgetting effects: a simulation study. Int. J. Prod. Res. 56 (2018) 3439-3461.

[4] S. Bhuniya, S. Pareek and B. Sarkar, A supply chain model with service level constraints and strategies under uncertainty. Alex. Engin. J. 60 (2021) 6035-6052.

[5] B.K. Dey, B. Sarkar, M. Sarkar and S. Pareek, An integrated inventory model involving discrete setup cost reduction, variable safety factor, selling price dependent demand, and investment. RAIRO-Oper. Res. 53 (2019) 39-57.

[6] B.K. Dey, S. Bhuniya and B. Sarkar, Involvement of controllable lead time and variable demand for a smart manufacturing system under a supply chain management. Exp. Sys. Appl. 184 (2021) 115464. 
[7] B.K. Dey, S. Pareek, M. Tayyab and B. Sarkar, Autonomation policy to control work-in-process inventory in a smart production system. Int. J. Prod. Res. 59 (2021) 1258-1280.

[8] O. Dowson, A. Philpott, A. Mason and A. Downward, A multi-stage stochastic optimization model of a pastoral dairy farm. Euro. J. Oper. Res. 274 (2019) 1077-1089.

[9] K. Forghani, A. Mirzazadeh and M. Rafiee, A price-dependent demand model in the single period inventory system with price adjustment. J. Ind. Eng. (2013) 1-9.

[10] B.B. Gardas, R.D. Raut and B. Narkhede, Evaluating critical causal factors for post-harvest losses (PHL) in the fruit and vegetables supply chain in India using the DEMATEL approach. J. Clean. Prod. 199 (2018) 47-61.

[11] J.P. Gayon, S. Vercraene and S.D.P. Flapper, Optimal control of a production-inventory system with product returns and two disposal options. Euro. J. Oper. Res. 262 (2017) 499-508.

[12] C.H. Glock and M.Y. Jaber, A multi-stage production-inventory model with learning and forgetting effects, rework and scrap. Comp. Ind. Engin. 64 (2013) 708-720.

[13] M. Golari, N. Fan and T. Jin, Multistage stochastic optimization for production-inventory planning with intermittent renewable energy. Prod. Oper. Manag. 26 (2017) 409-425.

[14] S. Gupta, A. Haq, I. Ali and B. Sarkar, Significance of multi-objective optimization in logistics problem for multi-product supply chain network under the intuitionistic fuzzy environment. Compl. Intell. Syst. 7 (2021) 2119-2139.

[15] R. Hammad, I.U. Khan, S. Asghar, S.H. Khalid, M. Irfan, I. Khalid, S.U. Shah, N. Sabir, A. Ali, A.M. Yousaf, T. Hussain, Y. Shahzad and U.F. Gohar, Multi-stage release matrices for potential antiplatelet therapy: assessing the impact of polymers and Sorb-Cel Mßon floating, swelling, and release behaviour. J. Drug Del. Sci. Technol. 55 (2020) 101387.

[16] A. Garai and B. Sarkar, Economically independent reverse logistics of customer-centric closed-loop supply chain for herbal medicines and biofuel. J. Clean. Prod. 334 (2022) 129977.

[17] M.S. Kim and B. Sarkar, Multi-stage cleaner production process with quality improvement and lead time dependent ordering cost. J. Clean. Prod. 144 (2017) 572-590.

[18] S. Kumar, B. Sarkar and A. Kumar, Fuzzy reverse logistics inventory model of smart items with two warehouses of a retailer considering carbon emissions. RAIRO-Oper. Res. 55 (2021) 2285-2307.

[19] A.S. Mahapatra, H.N. Soni, M.S. Mahapatra, B. Sarkar and S. Majumder, A continuous review production-inventory system with a variable preparation time in a fuzzy random environment. Mathematics 9 (2021) 747.

[20] L. Makarichi, W. Jutidamrongphan, K. Techato, The evolution of waste-to-energy incineration: A review. Renew. Sustain. Ener. Rev. 91 (2018) 812-822.

[21] A.H.M. Mashud and B. Sarkar, Retailer's joint pricing model through an effective preservation strategy under a trade-credit policy. RAIRO-Oper. Res. 55 (2021) 1799-1823.

[22] L. Meherishi, S.A. Narayana and K.S. Ranjani, Integrated product and packaging decisions with secondary packaging returns and protective packaging management. Euro. J. Oper. Res. 292 (2021) 930-952.

[23] M. Omair, S. Noor, M. Tayyab, S. Maqsood, W. Ahmed, B. Sarkar and M.S. Habib, The selection of the sustainable suppliers by the development of a decision support framework based on analytical hierarchical process and fuzzy inference system. Int. J. Fuz. Sys. 23 (2021) 1986-2003.

[24] S. Saha, I. Nielsen and I. Moon, Optimal retailer investments in green operations and preservation technology for deteriorating items. J. Clean. Prod. 140 (2017) 1514-1527.

[25] S.K. Sardar, B. Sarkar and B. Kim, Integrating machine learning, radio frequency identification, and consignment policy for reducing unreliability in smart supply chain management. Processes 9 (2021) 247.

[26] B. Sarkar, Mathematical and analytical approach for the management of defective items in a multi-stage production system. J. Clean. Prod. 218 (2019) 896-919.

[27] B. Sarkar, M. Ullah and M. Sarkar, Environmental and economic sustainability through innovative green products by remanufacturing. J. Clean. Prod. 332 (2022) 129813.

[28] M. Sarkar and B. Sarkar, How does an industry reduce waste and consumed energy within a multi-stage smart sustainable biofuel production system? J. Clean. Prod. 262 (2020) 121200.

[29] S. Kumar, M. Sigroha, K. Kumar and B. Sarkar, Manufacturing/remanufacturing based supply chain management under advertisements and carbon emission process. RAIRO-Oper. Res. (2022).

[30] B.R. Sarker, A.M.M. Jamal and S. Mondal, Optimal batch sizing in a multi-stage production system with rework consideration. Euro. J. Oper. Res. 184 (2008) 915-929.

[31] N. Saxena, B. Sarkar and S.R. Singh, Selection of remanufacturing/production cycles with an alternative market: a perspective on waste management. J. Clean. Prod. 245 (2020) 118935.

[32] A. Sepehri, U. Mishra, M.L. Tseng and B. Sarkar, Joint pricing and inventory model for deteriorating items with maximum lifetime and controllable carbon emissions under permissible delay in payments. Mathematics 9 (2021) 470.

[33] A.A. Shaikh, S.C. Das, A.K. Bhunia and B. Sarkar, Decision support system for customers during availability of trade credit financing with different pricing situations. RAIRO-Oper. Res. 55 (2021) 1043.

[34] Vandana, S.R. Singh, D. Yadav, B. Sarkar and M. Sarkar, Impact of energy and carbon emission of a supply chain management with two-level trade-credit policy. Energies 14 (2021) 1569.

[35] G. Sołowski, I. Konkol and A. Cenian, Production of hydrogen and methane from lignocellulose waste by fermentation. A review of chemical pretreatment for enhancing the efficiency of the digestion process. J. Clean. Prod. 267 (2020) 121721.

[36] M. Tayyab and B. Sarkar, Optimal batch quantity in a cleaner multi-stage lean production system with random defective rate. J. Clean. Prod. 139 (2016) 922-934. 
[37] M. Tayyab and B. Sarkar, An interactive fuzzy programming approach for a sustainable supplier selection under textile supply chain management. Comp. Ind. Eng. 155 (2021) 10716.

[38] I. Moon, W.Y. Yun and B. Sarkar, Effects of variable setup cost, reliability, and production costs under controlled carbon emissions in a reliable production system. Eur. J. Indust. Eng. (2022).

[39] M. Ullah and B. Sarkar, Recovery-channel selection in a hybrid manufacturing-remanufacturing production model with RFID and product quality. Int. J. Prod. Econ. 219 (2020) 360-374.

[40] M. Ullah, I. Asghar, M. Zahid, M. Omair, A. Alarjani and B. Sarkar, Ramification of remanufacturing in a sustainable threeechelon closed-loop supply chain management for returnable products. J. Clean. Prod. 290 (2021) 125609.

[41] C. Weller, R. Kleer and F.T. Piller, Economic implications of 3D printing: market structure models in light of additive manufacturing revisited. Int. J. Prod. Econ. 164 (2015) 43-56.

[42] D. Yadav, R. Kumari, N. Kumar and B. Sarkar, Reduction of waste and carbon emission through the selection of items with cross-price elasticity of demand to form a sustainable supply chain with preservation technology. J. Clean. Prod. 297 (2021) 126298.

\section{Subscribe to Open (S20) A fair and sustainable open access model}

This journal is currently published in open access under a Subscribe-to-Open model (S2O). S2O is a transformative model that aims to move subscription journals to open access. Open access is the free, immediate, online availability of research articles combined with the rights to use these articles fully in the digital environment. We are thankful to our subscribers and sponsors for making it possible to publish this journal in open access, free of charge for authors.

\section{Please help to maintain this journal in open access!}

Check that your library subscribes to the journal, or make a personal donation to the $\mathrm{S} 2 \mathrm{O}$ programme, by contacting subscribers@edpsciences.org

More information, including a list of sponsors and a financial transparency report, available at: https://www. edpsciences.org/en/maths-s2o-programme 